\title{
Co-exposure of Lead Acetate and Sodium Arsenite Causes Alteration in the Markers of Liver and Kidney Functions in Male Wistar Rats
}

\author{
Omowumi Oyeronke Adewale ${ }^{1, ~ *, ~ E k u n d a y o ~ S t e p h e n ~ S a m u e l}{ }^{2}$, Opeyemi Olusayo Oluwuyi, \\ Seun Funmilola Akomolafe ${ }^{3}$ \\ ${ }^{1}$ Department of Biochemistry, Faculty of Basic and Applied Sciences, Osun State University, Osogbo, Nigeria \\ ${ }^{2}$ Cancer Research and Molecular Biology Unit, Department of Biochemistry, College of Medicine, University of Ibadan, Ibadan, Nigeria \\ ${ }^{3}$ Department of Biochemistry, Faculty of Science, Ekiti State University, Ado Ekiti, Nigeria
}

Email address:

adewaleomowumi13@gmail.com (O. O. Adewale)

${ }^{*}$ Corresponding author

To cite this article:

Omowumi Oyeronke Adewale, Ekundayo Stephen Samuel, Opeyemi Olusayo Oluwuyi, Seun Funmilola Akomolafe. Co-exposure of Lead Acetate and Sodium Arsenite Causes Alteration in the Markers of Liver and Kidney Functions in Male Wistar Rats. Journal of Chemical, Environmental and Biological Engineering. Vol. 2, No. 1, 2018, pp. 32-39. doi: 10.11648/j.jcebe.20180201.16

Received: July 5, 2018; Accepted: July 27, 2018; Published: August 27, 2018

\begin{abstract}
Study aim: More is still to be known about the combinative effect of lead and arsenic compounds on critical organs. In this study, the effect of single and combined exposure to lead and arsenic on some biomarkers associated with liver and kidney functions in healthy Wistar rats was assessed. Method: The rats were divided into four groups $(n=5)$ and were treated with sodium arsenite or lead acetate individually or in combination for 14 days. Results: The results revealed that single exposure to either compound caused significant increase in the hepatic transaminases and alkaline phosphatase. Significant decrease in serum proteins and glucose concentration were also observed with morphological changes in the liver of treated rats as discovered by the photomicrographs from light microscopy indicating hepatotoxicity. Similarly, significant increase in the blood urea nitrogen (BUN) and creatinine concentration with simultaneous rise in the concentrations of serum potassium and sodium were observed. The photomicrographs of the kidney from light microscopy showed congestion in the interstitial spaces indicating compromised function of the kidney. The combination of the two metals demonstrated the enhanced effect on these parameters when likened with their individual treatments. Conclusion: This study therefore proves the enhanced toxicity induced by co-exposure to lead acetate and sodium arsenite among biomarkers of liver and kidney functions in Wistar rats.
\end{abstract}

Keywords: Lead Acetate, Sodium Arsenite, Liver Biomarkers, Kidney Biomarkers, Histopathology and Toxicity

\section{Introduction}

Lead is a very important toxic heavy metal in the environment, it is abundantly distributed globally. Lead together with its compounds are important yet dangerous environmental chemicals. [1] It has important properties like malleability, ductility, poor conductibility and resistance to corrosion which make it highly useful. It is nonbiodegradable, this property makes it and its compounds accumulate in the environment thereby causing a lot of hazards. Human exposure to lead and its compounds is possible mostly in lead related occupations, eventhough, there has been a discontinuous widespread use of lead in many Countries, some industries like car repair, battery manufacturing and recycling, refining and smelting industries e.t.c., consider its use inevitable. Therefore, human exposure to toxicities induced by lead and its compounds remain unavoidable. Arsenic is another element that has raised concern from both environmental and human health stand points. Humans may get exposed to arsenic in water from wells drilled into arsenic-rich ground strata or in water contaminated by industrial or agrochemical waste and therefore, predisposed to its induced toxicities. [2]

The most important target organs for series of toxicants have been the kidney and the liver due to the critical roles of detoxification and metabolism they perform. [3-4] Changes 
in the concentrations of biomarkers such as the blood urea nitrogen (BUN), creatine, electrolytes, albumin and activities of some enzymes incuding alaninine amino transferase (ALT), aspartate amino transferase (AST), alkaline phosphatase and gamma glutaryl transferase (GGT) are some of the useful measurements in the assessment of the pathological changes associated with these organs. [5-6] Cases of liver disease are also frequently seen with increasing concentrations of serum triglycerides [7] and a decline in glycemia has been described in Wistar rats with hepatic necrosis, lipidosis, neoplasia and cirrhosis. [8]

The toxic effects induced by individual exposure to arsenic and lead on hepatic and renal tissues have been reported [9] but humans get exposed simultaneously to more than one toxicant in the atmosphere. Co-exposure to arsenic and lead has been reported in Nigeria and some west African countries to be through the consumption of "calabash chalk which was formally used by pregnant and nursing mothers to cure morning sickness before it was banned. [10] Also, reports exist on occupational and environmental co-exposure to many other heavy metals including $\mathrm{As}$ and $\mathrm{Pb}$, [11-14] however, there is dearth of detailed information as regards the extent of the induced toxicities in organs critical for their metabolism and detoxification. Due to continuous exposure to various combined toxicants, it may not be a misguided research priority to assess the toxicological effects induced by mixture of these toxicants on these crucial organs, hence, we carried out this work.

\section{Materials and Methods}

\subsection{Chemicals}

Sodium arsenite $\left(\mathrm{Na}_{2} \mathrm{AsO}_{2}\right.$, Mol.wt 129.9 As 57.6\% CAS No 7784-46-5; Sigma Chemical Co., St. Louis, MO) and lead acetate $\left(\mathrm{CH}_{3} \mathrm{COO}\right) 2 \mathrm{~Pb} .3 \mathrm{H}_{2} \mathrm{O}$, mol.wt 379.33, 99.999\%, CAS No. 6080-56-4; Aldrich Chemical Co. Inc. St. Paul Avenue Wisconsin USA). All other reagents and chemicals were of analytical grade and were obtained from Sigma Chemical Co. St. Louis, Mo. USA.

\subsection{Experimental Design}

Adult male albino rats (weighing 120 - 150 g) were obtained from the animal breeding unit at Department of Biochemistry, Obafemi Awolowo University, Ile-Ife, Osun State, Nigeria, and were housed in cages, at room temperature $\left(24-27^{\circ} \mathrm{C}\right)$, relative humidity $60-70 \%$, and $12-$ hour light/dark cycle. Food (pellet rat chow) and water were available ad libi-tum. Animals were cared according to US National Institute of Health ethical guidelines. After 2 weeks of acclimatization, animals were randomly divided into four groups of five animals each: Group I (C) given $1 \mathrm{ml} / \mathrm{kg}$ body weight distilled water, group II $(\mathrm{Pb})$ given $60 \mathrm{mg} / \mathrm{kg}$ body weight of lead acetate, group III (As) given $2.5 \mathrm{mg} / \mathrm{kg}$ body weight of sodium arsenite and group $\operatorname{IV}(\mathrm{Pb}+\mathrm{As})$ given $60 \mathrm{mg} / \mathrm{kg}$ body weight of lead acetate and $2.5 \mathrm{mg} / \mathrm{kg}$ body weight of sodium arsenite. Treatment was done orally and once daily for 14 days. Lead acetate and sodium arsenite were dissolved in distilled water and were administered at a dose of $60 \mathrm{mg} / \mathrm{kg}$ and $2.5 \mathrm{mg} / \mathrm{kg}$ body weight respectively. The choice of lead acetate dosage was according to the report of a study, this dose corresponds to $1 / 10^{\text {th }}$ of the reported $\mathrm{LD}_{50}$ [15] while the dosage of sodium arsenite corresponded to $1 / 10^{\text {th }}$ of the reported oral $\mathrm{LD}_{50}$ of sodium arsenite. [16] After the treatment period, animals were fasted overnight and sacrificed 24 hours after the last dose under light ether anesthesia. Blood samples were obtained by heart puncture and centrifuged at $3000 \mathrm{~g}$ for 10 minutes. The clear nonhemolyzed sera were stored at $20^{\circ} \mathrm{C}$ till subsequent measurements. The liver and kidney tissues were quickly excised and washed in cold saline solution, blotted on filter papers to remove adhering blood, weighed and kept in $10 \%$ formalin for histological examination.

\subsection{Determination of Serum Hepatic Function Biomarkers}

The hepatic function biomarkers: ALT and AST were determined following the principle reported by Reitman and Frankel. [17] GGT and ALP were determined following the principles reported by Szasz and Englehardt respectively. [18-19] Total protein concentrations of the serum were determined according to Biuret method as described by Gornal et al. [20] Albumin concentration were determined following the principle reported by Grant, [21] triglycerides concentration was determined by following the principle reported by Bucolo and David, [22] and glucose concentration was determined through the procedure reported by Trinder. [23]

\subsection{Determination of Renal Function Biomarkers}

The renal function biomarkers: BUN and creatinine concentrations were determined following the principles described by Weatherburn and Henry respectively. [24-25] Serum sodium and potassium concentrations were obtained following the method described by Maruna and Trinder with little modification. [26]

\subsection{Histopathological Analysis}

The liver and kidney were excised from the animals after sacrificed and stored in $10 \%$ formalin solution, for tissue sections and subsequent histopathological examination. The tissues were then embedded in paraffin. Rotary microtome was used to collect five micrometer-thick paraffin sections and tissues were thereafter stained by Hematoxylin and Eosin (H\&E). The specimens were examined and photographed under light microscope.

\subsection{Statistical Analysis}

The data were expressed as mean \pm standard deviation after analysis by one-way analysis of variance (ANOVA) with the aid of Statistical Package for Social Sciences (SPSS) software, SPSS Inc., Chicago, Standard version 17.0. Differences between mean values of different groups were considered statistically significant at $\mathrm{P}<0.05$. 


\section{Results}

\subsection{Effect of Lead Acetate and Sodium Arsenite on Body and Organ Weights}

The differences in body weight gained by the different groups with their relative liver and kidney weights were presented (Table 1). Both lead acetate and lead acetate + sodium arsenite groups gained weights significantly when compared with control $(\mathrm{P}<0.05$; ANOVA) while sodium arsenite group experienced significantly low weight gain as compared with control (Table 1). There are no significant changes in the relative liver and kidney weights except in the sodium arsenite group only.

Table 1. Body and organ weights profile of rats exposed to lead acetate and sodium arsenite.

\begin{tabular}{llll}
\hline Groups & Body weight gained (\%) & Relative Liver weight (\%) & Relative Kidney weight (\%) \\
\hline $\mathrm{Control}$ & 19.8 & $2.40 \pm 0.33$ & $2.40 \pm 0.33$ \\
$\mathrm{~Pb}$ & $26.60^{*}$ & $2.73 \pm 0.25$ & $2.73 \pm 0.25$ \\
$\mathrm{As}$ & $11.20^{*}$ & $3.11 \pm 0.40^{*}$ & $3.11 \pm 0.40^{*}$ \\
$\mathrm{~Pb}+\mathrm{As}$ & $23.70^{*}$ & $2.74 \pm 0.45$ & $2.74 \pm 0.45$ \\
\hline
\end{tabular}

The values are expressed as mean $\pm \mathrm{SD}, \mathrm{n}=5$ and *significantly different at $\mathrm{P}<0.05$ from control. Control: given $1 \mathrm{ml} / \mathrm{kg}$ body weight distilled water, $\mathrm{Pb}$ : given $60 \mathrm{mg} / \mathrm{kg}$ body weight of lead acetate, As: given $2.5 \mathrm{mg} / \mathrm{kg}$ body weight of sodium arsenite and $\mathrm{Pb}+\mathrm{As}$ : given $60 \mathrm{mg} / \mathrm{kg}$ body weight of lead acetate and $2.5 \mathrm{mg} / \mathrm{kg}$ body weight of sodium arsenite.

\subsection{Serum Hepatic Function Biomarkers Analysis}

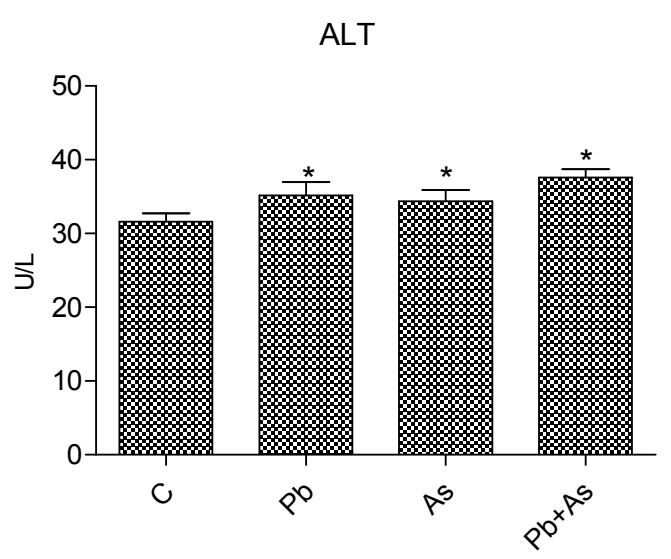

Figure 1. Effects of lead acetate and sodium arsenite on Alanine aminotransferase (ALT) activity in rats. The values are expressed as mean \pm $S D$ for $n=5$. *significantly $(P<0.05)$ different from control. For details see legend in Table 1.

Treatment of rats with lead acetate and sodium arsenite individually and in combination resulted in significant increase in the activities of serum ALT, AST, ALP and GGT and significant decrease in the concentrations of albumin, glucose and total protein $(\mathrm{P}<0.05$; ANOVA) when compared with the control (Figures 1-7). Also, the combination and sodium arsenite singly increase triglyceride concentration $(35.60 \pm 1.67 ; 34.80 \pm 3.89$ respectively) while laed acetate $(32.80 \pm 2.16)$ singly caused a decrease when compared with control $(33.00 \pm 1.87)$, although there were no significant differences in triglyceride concentrations between the means.

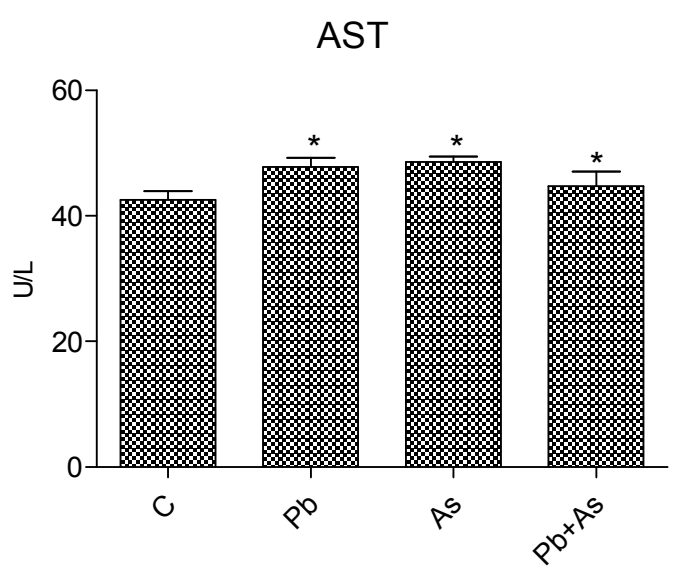

Figure 2. Effects of lead acetate and sodium arsenite on Aspartate aminotransferase (AST) activity in rats. The values are expressed as mean \pm $S D$ for $n=5$. *significantly $(P<0.05)$ different from control. For details see legend in Table 1.

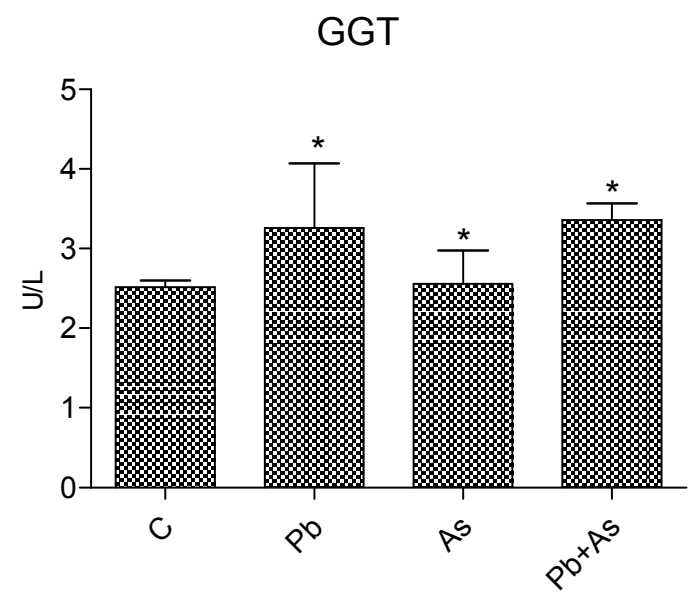

Figure 3. Effects of lead acetate and sodium arsenite on Gamma glutaryl transferase (GGT) activity in rats. The values are expressed as mean $\pm S D$ for $n=5$. *significantly $(P<0.05)$ different from control. For details see legend in Table 1. 
ALP

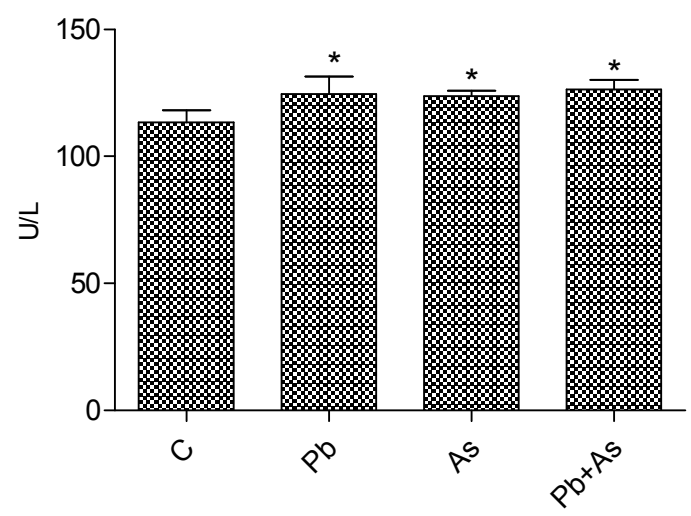

Figure 4. Effects of lead acetate and sodium arsenite on Alkaline phosphatase (ALT) activity in rats. The values are expressed as mean $\pm S D$ for $n=5$. *significantly $(P<0.05)$ different from control. For details see legend in Table 1.

\section{Glucose}

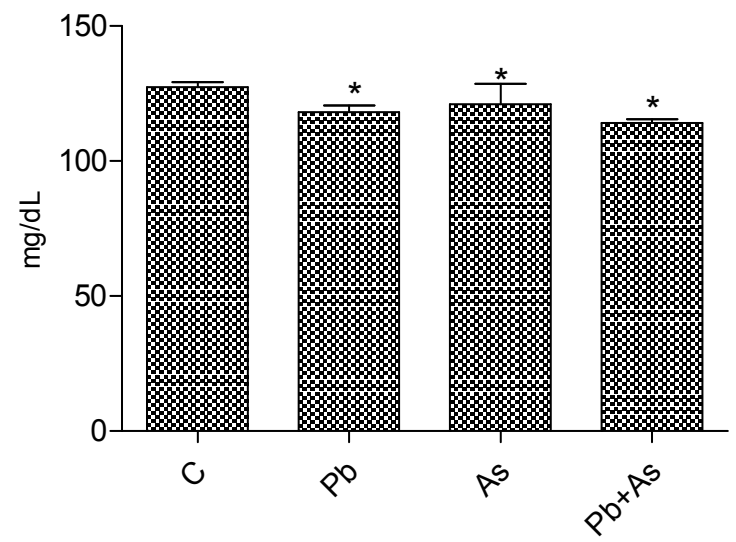

Figure 5. Effects of lead acetate and sodium arsenite on glucose concentration in rats. The values are expressed as mean $\pm S D$ for $n=5$. *significantly $(P<0.05)$ different from control. For details see legend in Table 1.

\section{Total protein}

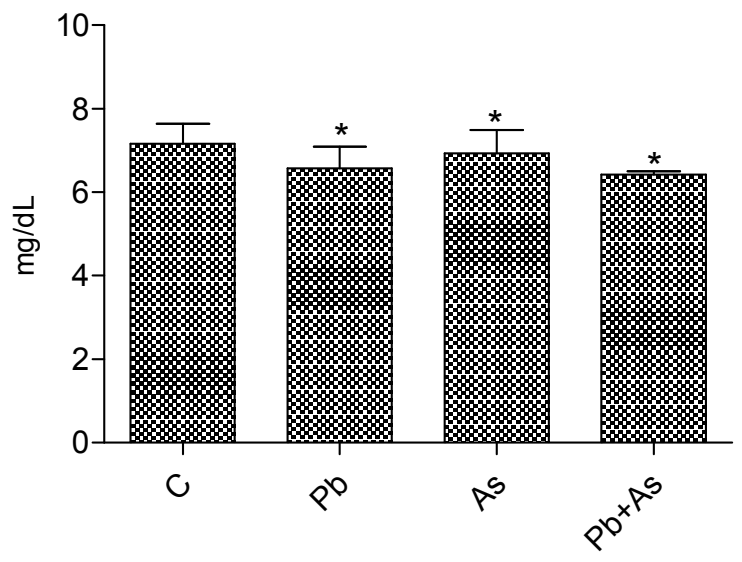

Figure 6. Effects of lead acetate and sodium arsenite on total protein concentration in rats. The values are expressed as mean $\pm S D$ for $n=5$. *significantly $(P<0.05)$ different from control. For details see legend in Table 1.

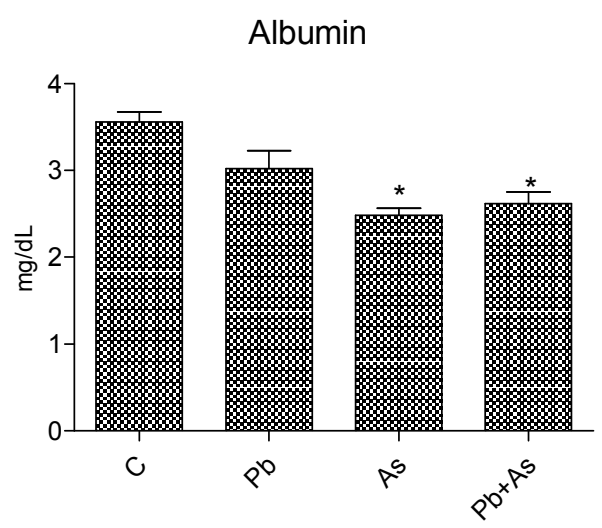

Figure 7. Effects of lead acetate and sodium arsenite on albumin concentration in rats. The values are expressed as mean $\pm S D$ for $n=5$. *significantly $(P<0.05)$ different from control. For details see legend in Table 1.

\subsection{Serum renal Function Biomarkers Analysis}

Significant increase in the concentrations of serum urea, creatinine, sodium and potassium were observed $(\mathrm{P}<0.05$; ANOVA) following treatment of rats with lead acetate and sodium arsenite individually and in combination when compared with the control (Figure 8-11).

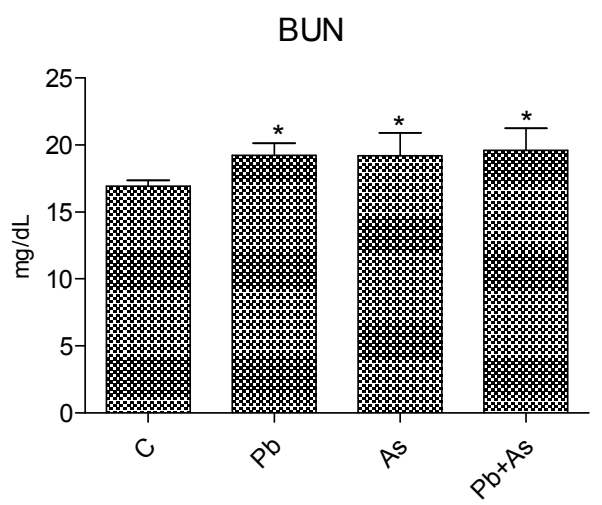

Figure 8. Effects of lead acetate and sodium arsenite on serum urea concentration in the blood of the exposed rats. Values are expressed as mean $\pm S D, n=5$ and *significantly $(P<0.05)$ different from control. For details see legend in Table 1.

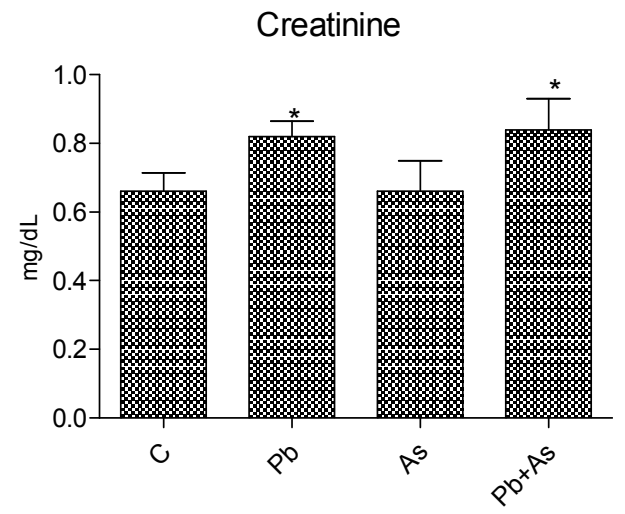

Figure 9. Effects of lead acetate and sodium arsenite on serum creatinine concentration in the blood of the exposed rats. Values are expressed as mean $\pm S D, n=5$ and $*$ significantly $(P<0.05)$ different from control. For details see legend in Table 1. 
$\mathrm{Na}$

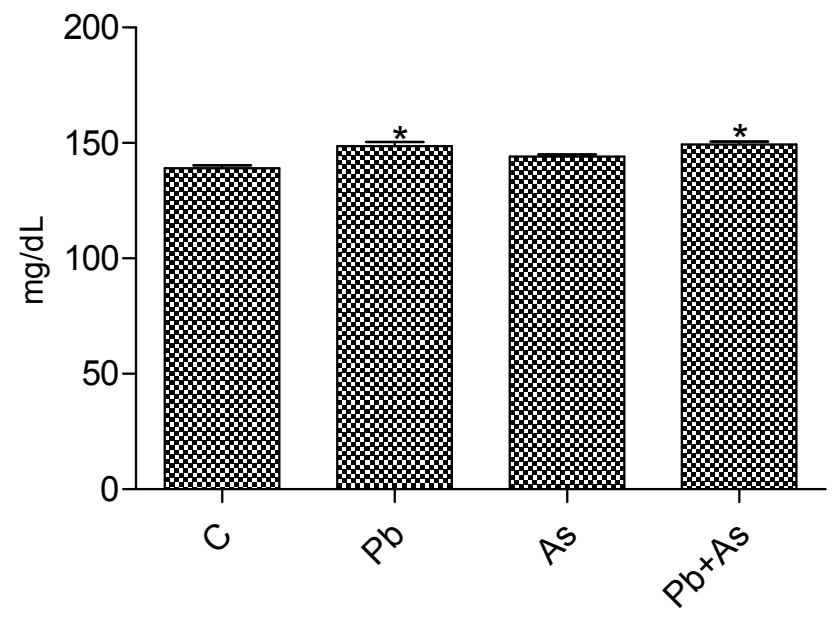

Figure 10. Effects of lead acetate and sodium arsenite on plasma sodium (Na) concentration in the blood of the exposed rats. Values are expressed as mean $\pm S D, n=5$ and *significantly $(P<0.05)$ different from control. For details see legend in Table 1
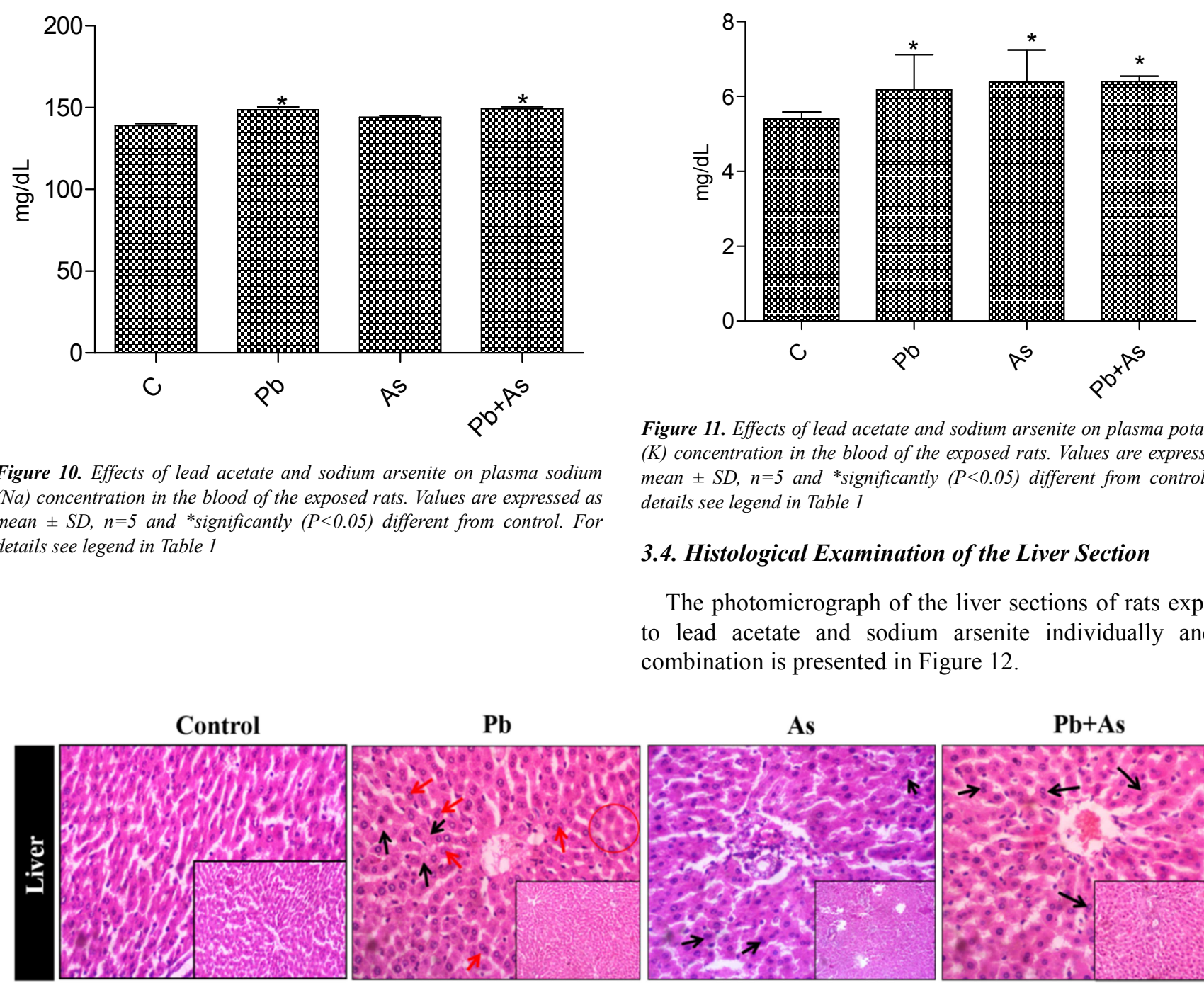

Figure 11. Effects of lead acetate and sodium arsenite on plasma potassium $(K)$ concentration in the blood of the exposed rats. Values are expressed as mean $\pm S D, n=5$ and *significantly $(P<0.05)$ different from control. For details see legend in Table 1

\subsection{Histological Examination of the Liver Section}

The photomicrograph of the liver sections of rats exposed to lead acetate and sodium arsenite individually and in combination is presented in Figure 12.

Figure 12. Representative photomicrographs of liver sections (viewed under light microscope at $\times 400$ magnification). Control (distilled water): showing no visible lesion, $\mathrm{Pb}$ (lead acetate): showing vacuolar hepatocellular degeneration (black arrows) and necrosis (circled areas) around the centrilobular to midzonal region in addition to moderately increased frequency of binucleate or dividing cells (red arrows). As (sodium arsenite): showing moderately increased frequency of binucleate or dividing cells (black arrows), $\mathrm{Pb}+\mathrm{As}$ (lead acetate plus sodium arsenite): showing increased number of mitotic hepatocyte as evidenced by bi-nucleate and tri-nucleate cells (black arrows).

\subsection{Histological Examination of the Kidney Section}

The changes obtained in the kidney sections of exposed rats were presented (Figure 13).
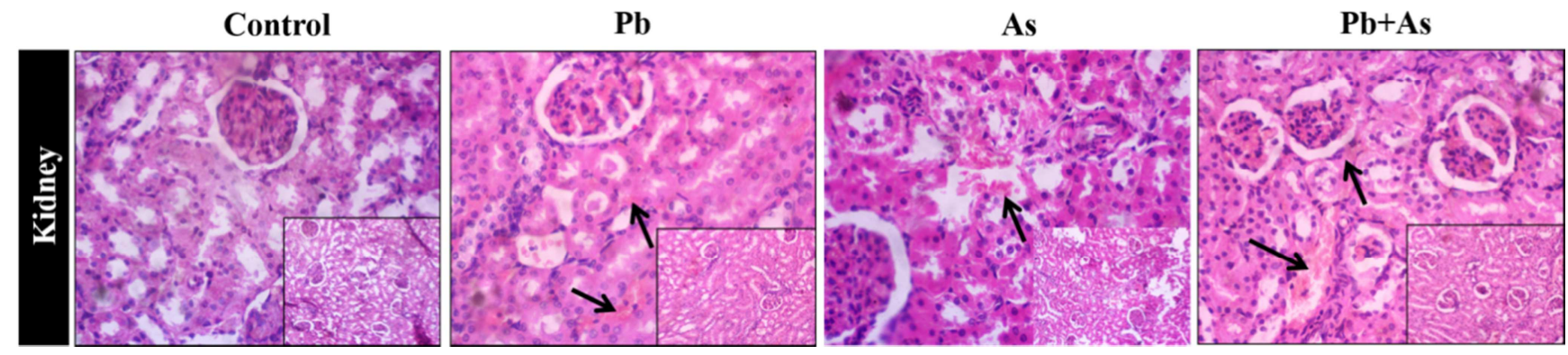

Figure 13. Representative photomicrographs of kidney sections (viewed under light microscope at $\times 400$ magnification). Control (distilled water): showing no visible leision, Pb (lead acetate): showing moderate congestion of tubule-intersttial spaces (arrow). As (sodium arsenite): showing moderate congestion in the interstitial spaces (arrow). $\mathrm{Pb}+$ As (lead acetate plus sodium arsenite): showing severe widespread renal interstitial congestion (arrows). 


\section{Discussion}

Contamination of the environment with heavy metals and some other contaminants have been related to factors predisposing exposed individuals to development of several health issues including cancers. [27, 28-29] Lead and arsenic are both heavy metals which are well-established for their induced environmental toxicities. [30-32] Exposure of humans to both chemicals is still far from elimination since many industries find their use inevitable. Researches focus mainly on the effects of the individual heavy metal while only few which examine combined effects of these environmental contaminants provided very few data hence the reason this study was conducted to present more data on the combined toxic effect of the two metals.

Treatment with either lead or sodium arsenite caused a significant increase in the final body weight when compared with control at $(\mathrm{P}<0.05)$ (Table 1). The combination group gained more weight significantly than sodium arsenite group but less than lead acetate group. No significant changes in the relative organ weights were obtained except in the sodium arsenite group only.

In order to assess the proper functioning of the liver, the concentrations of various different proteins and enzymes are measured in the blood. These substances are either synthesized by the liver cells or they are released when liver cells are damaged. Some of these substances were measured in this study.

Alanine aminotransferase catalyzes the transfer of amino groups to form the hepatic metabolite oxaloacetate. In both acute and chronic hepatocellular injuries, the serum activity of the ALT have been reported to be significantly elevated. [6] In the present study, lead acetate and sodium arsenite individually induced significantly higher ALT activity (Figure 1a) compared with the control while coadministration of both metals increased the activity of the enzyme suggesting enhanced toxicity induced by both metals. AST, GGT and ALP have also been frequently used as measures for liver function, an increase in their activities is implicated in liver damage. [33] In this study there is a significant increase in induction of the enzymes by lead acetate and sodium arsenite when compared with the control these increase got significantly enhanced with coadministration of both metals (Figure 1b-d). Significant increase in these enzymes activities is buttressing that there is enhanced liver damage. These data on the hepatic enzymes are in agreement with earlier report. [14]

Even though there was an observed increase in the concentration of triglycerides in the lead acetate and sodium arsenite groups individually and in combination as compared with the control, the increase is insignificant. Increase in triglyceride concentration has been associated with significant lipid accumulation in the liver. [7] A significant increase in triglyceride concentration following exposure to lead acetate has also been reported [9], however, this is contradictory to the result of this study, the reason for the contradiction is not really clear. The insignificant increase in triglyceride concentration may mean that the toxicants at the tested doses are not associated with lipid accumulation as observed in this study.

A decline in blood glucose concentration and compromised function is not popular as the glucose concentration remains normal in rats with hepatopathy. $[9,28]$ However, a significant decrease in glucose concentration has been earlier linked with hepatic necrosis, neoplasia and cirrhosis as described in Wistar rat. [8] In the present study, the significant decrease seen in both sodium arsenite and lead acetate (Figure 1e) may not be unrelated to their induced hepatotoxicity. The glucose concentration was further decreased in the combination doses signifying enhanced hepatotoxicity. This is not in agreement with the report of the work with a higher dose of arsenic, however, the low concentration of glucose might be related to the reduced function of the liver or inability to degrade glycogen to glucose at a normal rate. [34]

From this study also, in the lead and arsenic groups, individually and in combination, serum total protein and albumin levels were found to be significantly decreased $(p<0.05)$ as compared with the control (Figures 6 and 7). Earlier report has linked lead sodium arsenite exposure to serum total protein and albumin decrease. [9, 34] Many substances have been reported to be capable of binding to serum proteins, albumin inclusive. [35-36] The significant decrease in the total protein and albumin concentration might be related to the binding ability of lead and arsenic to the blood protein hence reducing their concentration in the serum. Also, since the liver is the primary organ for protein synthesis, the compromised function of the liver might be the reason for the significant decrease in these proteins

The kidney glomerulli serves as an important organ which filter out urea from the blood, therefore the concentration of urea in the serum is being constantly used as a clinical index for determining renal function. [37] There was a significant increase in the blood urea concentration (Figure 8) in this study in lead acetate and sodium arsenite groups which was enhanced by both metals, this may be an indication that the function of the kidney has been compromised, however, since overproduction of urea has also been associated with non-renal factors, we assessed other biomarkers of renal function to ascertain this inference. [38]

Significant increase in creatinine concentration is associated with an assumption of renal failure diagnosis. [39] The significant increase in creatinine concentration (Figure 9) observed in this study could serve as an increased evidence of the compromised kidney function. The significant increase in plasma electrolytes that is the plasma sodium and potassium (Figure 10 and 11) in the toxicant groups observed in this study suggests a perturbation in the acid-base and water balance which are strictly controlled by the kidney. [40] This provides confirmation to this proof of kidney function impairment.

Histological examination of the liver tissues (Figure 12) from the exposed rats revealed vacuolar hepatocellular degeneration and necrosis around the centrilobular to midzonal region in the group that were administered lead acetate. 
Though there was no visible lesion in the sodium arenite group, combination of sodium arsenite with lead acetate resulted in increased number of mitotic hepatocyte as evidenced by binucleate and tri-nucleate cells suggesting increase in proliferation of the hepatocytes beyond the control group. Lead exposure has been previously linked to increase in cell proliferation. [41] Any substance that has capacity to induce increase in cell proliferation can be a potential carcinogen. Since humans get exposed to more than one environmental toxicant, the result of study is an implication that combined doses of these toxicants might induce carcinogenesis. In the kidney (Figure 13), lead acetate caused moderate congestion of tubule-intersttial spaces and sodium arsenite induced moderate congestion in the interstitium. These conditions become more severe when these toxicants were combined buttressing the afore mentioned fact.

There were reports on the contamination of certain environments with arsenic, lead and poly aromatic hydrocarbons. [13] Several reports on the different organs toxicity induced by the metals (arsenic and lead) abound.[4245] The report on the interaction between arsenic and lead acetate resulting in significant increase in induction of micronuclei and liver enzyme biomarkers also exists but information is scarce as regards the combined effects of arsenic and lead on detailed markers for the function of these two indispensable organs in the aspect of metabolism and detoxification. [14]

Here, it may be recommended that combined doses of arsenic and lead elicited their synergistic effect by lowering the concentration of serum proteins and glucose and by increasing the proliferative ability of the hepatocytes. The combined doses also resulted in the perturbation of the electrolytes balance and lowered creatinine clearance capacity in the kidney of the treated rats. This report has not existed before now regarding sodium arsenite and lead acetate.

\section{Conclusion}

The present study suggests that lead and arsenic exhibited significant toxicity during individual exposure whereas coexposure to these metals demonstrated the enhanced effect on these parameters when likened with individual treatments in male rats. Hence, this study proves the enhanced toxicity induced by the combination of lead acetate and sodium arsenite among biomarkers of liver and kidney functions.

\section{Conflict of Interest}

The authors declare that there is no conflict of interest.

\section{References}

[1] Mahaffay KK. (1990). Introduction: Advances in lead research: Implications for environmental health. Environ. Health perpect. 89: 95-100.
[2] Parvez F, Chen Y, Argos M, Hussain AZ, Momotaj H, Dhar R, van Geen A, Graziano JH, Ahsan H. (2006). Prevalence of arsenic exposure from drinking water and awareness of its health risks in a Bangladeshi population; results from a large population-based study. Environ. Health Perspect. 114(3):35559.

[3] Omiecinski CJ, John P, Vanden H, Gary H. Perdew, Jeffrey M.P. (2011). "Xenobiotic Metabolism, Disposition, and Regulation by Receptors: From Biochemical Phenomenon to Predictors of Major Toxicities.” Toxicol Sci. 120 (SUPPL. 1). https://doi. org/10.1093/toxsci /kfq338.

[4] Malaguarnera G, Emanuela C, Maria G, et al. (2012) "Toxic Hepatitis in Occupational Exposure to Solvents." World Journal of Gastroenterology 18 (22): 2756-66.

[5] Durham AE, Smith KC, Newton JR. (2003). An evaluation of diagnostic data in comparison to the results of liver biopsies in mature horses. Equine Vet J. 35(6):554-9.

[6] Kim WR, Steven LF, Adrian MD, Adrian MD, Henry CB. (2008). "Serum Activity of Alanine Aminotransferase (ALT) as an Indicator of Health and Disease." J Hepatol. https: //doi. Org/10.1002/hep.22109.

[7] Mogg TD, Palmer JE. (1995). Hyperlipidemia, hyperlipemia, and hepatic lipidosis in American Miniature Horses: 23 cases (1990-1994). J Am Vet Med Assoc. 207: 604-607.

[8] West HJ. (1994). The evaluation of hepatobiliary disease in horses and cattle. FRCVS Thesis, London.

[9] Offor SJ, Mbagwu HOC, Orisakwe OE. (2017). Lead Induced Hepato-Renal Damage in Male Albino Rats and Effects of Activated Charcoal. Front Pharmacol https://doi.org/10.3389/fphar.2017.00107.

[10] National Agency for Food and Drug Administration and Control (2006) available at: www.nafdacni geria.org

[11] Nehez M, Lorencz R, Desi I. (2000). Simultaneous action of cypermethrin and two environmental pollutant metals, cadmium and lead, on bone marrow cell chromosomes of rats in subchronic administration. Ecotoxicol Environ Saf. 45: 55-60.

[12] Englyst V, Lundstrom NG, Gerhandsson L, Rylander L, Nordberg G. (2001). Lung cancer risks among lead smelter workers also exposed to arsenic. Sci. Total Environ. 273(13):77-82.

[13] Lambert TW, Lane S,. (2004). "Lead, Arsenic, and Polycyclic Aromatic Hydrocarbons in Soil and House Dust in the Communities Surrounding the Sydney, Nova Scotia, Tar Ponds." Environ. Health perpect. 112 (1): 35-41.

[14] Odunola OA, Akinwumi KA,; Ogunbiyi B, Tugbobo O. (2007) Interaction and Enhancement of the Toxic Effects of Sodium Arsenite and Lead Acetate in Wistar Rats. Afr J Biomed Res. $10 ; 59-65$.

[15] Sujatha K, Srilatha C, Anjaneyulu Y, Amaravathi P. (2011). "Lead acetate induced neurotoxicity in wistar albino rats: A pathological, immunological, and ultrastructural studies." Journal of pharma and bio science. 2: 459-62.

[16] Escribano A, Revilla M, Hernandez ER, Seco C, GonzalezRiola J, Villa LF, Rico H. (1997). Effect of lead on bone development and bone mass: a morphometric, densitometric and histomorphometric study in growing rats. Calcif. Tissue Int. 60: 200-203. 
[17] Reitman S, Frankel S. (1957). A colorimetric method for determination of serum glutamic oxaloacetic and glutamic pyruvic transaminases. Am. J. Clin. Pathol. 28 56-62.

[18] Szasz G. (1969). A kinetic photometric method for serum gamma glutamyl transferase. Clin Chem. 124: 124-136.

[19] Englehardt A. (1970). Measurement of alkaline phosphatase. Aerztl Labor 16:42. 1

[20] Gornal AG, Barawill JC, David MM. (1949). Determination of serum protein by means of Biuret reaction $\mathrm{J}$ Biol Chem. 177: 751-761.

[21] Grant GH. (1987). Amino acids and protein; fundamentals of clinical chemistry. In: Tietz NW (ed) WB Saunders company Philadelphia USA: pp. 328-329.

[22] Bucolo G. and David H. (1973). Quantitative Determination of Serum Triglycerides by Use of Enzymes. Clinical Chemistry, 19, 476-482.

[23] Trinder P. (1969). Determination of blood glucose using an oxidase-peroxidase system with a non-carcinogenic chromagen. J Clin Pathol. 22:158-161.

[24] Weatherburn MW. (1967). Phenol hypochlorite reaction for determination of serum urea. Analyt. Chem. 39 (8):939-971.

[25] Henry RF. (1974). Clinical Chemistry Principle and Techniques. 2nd edition, published by Harper and Row, New York.

[26] Maruna RFL, Trinder P. (1958). Analysis of serum sodium and potassium ions. Clin Chim Acta. 2: 581-585.

[27] Tchounwou PB, Clement GY, Anita KP, Dwayne JS. (2012). "Heavy Metals Toxicity and the Environment." In Molecular, Clinical and Environmental Toxicology. https://doi.org/10. 1007/978-3-7643-8340-4_6.

[28] Orisakwe OE. (2014). "Lead and Cadmium in Public Health in Nigeria Physicians Neglect and Pitfall in Patient Management. North American Journal of Med Sci. 6(2): 6170 .

[29] Hu B, Xiaolin J, Jie H, Dongyun X, Fang X, Yan L. (2017). "Assessment of Heavy Metal Pollution and Health Risks in the Soil-Plant-Human System in the Yangtze River Delta, China." Int J Environ Res Public Health 14(9).

[30] Elias RW. (1985). Lead exposure in human environment. In: Mahaffey K Dietary and environmental lead: Human health effects. Elsevier Amsterdarm-New York-Oxford. pp 79-107.

[31] Abernathy CO, Liu YP, Long-Fellow D, Aposhian HV, Beck B, Fowler B, Goyer R, Menzer R, Rossman T, Thompson C. Waalkes M. (1999). Arsenic: Health effects, Mechanism of actions and research issue. Environ Health Perspect. 107: 593597.

[32] Poma A, Pittalugal E, Tucci A. (2003). Lead acetate genotoxicity on human melanoma cells in vitro. Melanoma Res. 13(6): 563-566.
[33] Concepción NM, Pilar MM, Martín A, Jiménez J, Pilar UM. (1993). Free radical scavenger and antihepatotoxic activity of Rosmarinus tomentosus. Planta Med. 59(4):312-4.

[34] Klibet F, Amel B, Mohamed K, Abdelfattah E, Cherif A, Mahfoud M. (2016). "Oxidative Stress-Related Liver Dysfunction by Sodium Arsenite: Alleviation by Pistacia Lentiscus Oil.” Pharm Biol. https://doi.org/10.3109/13880209.2015.1043562.

[35] De Smet R, Van Kaer J, Van Vlem B, De Cubber A, Brunet P, Lameire N, Vanholder R. (2003). "Toxicity of Free P-Cresol: A Prospective and Cross-Sectional Analysis." Clin Chem. 49(3): 470-78.

[36] Tarhoni MH, Timothy L, David ER, Wayne GC. (2008). "Albumin Binding as a Potential Biomarker of Exposure to Moderately Low Levels of Organophosphorus Biomarkers. https://doi.org/10.1080/13547500801973563.

[37] Mitchell HR, Kline W. (2006). Core curriculum in nephrology, Renal Function Testing. Am J Kidney Dis. 47:174-183.

[38] Pagana KD. (1998). Mosby's Manual of Diagnostic and Laboratory Tests. St. Louis Mosby, Inc.

[39] Edmund L, David J. (2006). Kidney function tests. In: Carl AB, Edward R, David E, editors. Tietz Textbook of clinical chemistry and molecular diagnostics. 4th ed. New Delhi: Elsevier Inc; pp. 797-808.

[40] James S, Mitchel G. (2006). Physiology and disorder of water electrolytes and acid base metabo-lism. In: Carl AB, Edward R, David E, editors. Tietz Textbook of clinical chemistry and molecular diagnostics. 4th ed. New Delhi: Elsevier Inc;. pp. $1747-1776$

[41] Calabrese EJ, Baldwin LA. (2008). Lead-Induced Cell Proliferation and Organ-Specific Tumori-genicity. Drug Metab Rev. 24:3.

[42] Garu U., Sharma R. and Barber I. (2011). Effect of lead toxicity on developing testis of mice. IJPSR.09758232.2(9).2403-07

[43] Assi MA., Abba Y, Abdulkhaleq LA. et al. (2018). Effect of powdered seed of Nigella sativa administration on sub-chronic and chronic lead acetate induced hemato- biochemical and histopathological changes in Sprague Dawley rats. Comp Clin Pathol (2018) 27: 705.

[44] Jegede AI., Ajadi M., Akinloye O. (2013). Modulatory effects of Kolaviron (Garcina kola extract) on spermogram and reproductive system of adult male Wistar rats in lead acetate induced toxicity. J. Toxicol Environ Sci.:5(7);121-130.

[45] Dikhil M, Al-Khalifa M, Al-Quraishy S, Zrieq R, Moneim A (2016). Indigofera longifolia mitigates lead-acetate-induced kidney damage and apoptosis in a rat model. Drug Des, Dev. Therapy 10:1847-1856. 